\title{
Effects of hepatocyte growth factor on differentiation and cMET receptor expression in the promyelocytic HL60 cell line
}

\author{
S C Afford, T Kakoullis, J Oates, J Crocker, A J Strain
}

\begin{abstract}
Aim-To determine the effects of hepatocyte growth factor (HGF) on myeloid cell differentiation and cMET expression using the promyelocytic HL60 cell line. Methods-HL60 cells cultured with purified recombinant HGF, dimethyl sulphoxide (DMSO), or 12-O tetradecanoylphorbol-13-acetate (TPA) were immunostained for the differentiation markers, human neutrophil elastase (HNE), cathepsin B, MAC387, or the receptor for hepatocyte growth factor (cMET).
\end{abstract}

Results-HGF treated cells were positive on staining for cathepsin B and MAC387, but were negative for $H N E$, indicating monocytic differentiation. HGF treated cells had the morphology of monocytes but continued to divide at the same rate as control cells and remained non-adherent. DMSO treated cells were positive for $\mathrm{HNE}$ and cell numbers were reduced, confirming myeloid differentiation. TPA treated cells were positive for cathepsin $B$ and MAC387, cell numbers were reduced, and the cells became adherent, confirming terminal monocytic differentiation. Untreated HL60 cells were weakly positive for cMET at the start of the culture period and expression increased after 72 hours. Cells treated with HGF, DMSO, or TPA were also positive for cMET.

Conclusions-These data suggest that HGF induced partial monocytic differentiation in HL60 cells. In addition, expression of cMET by HL60 cells occurs at an early stage in myelomonocytic cells and is maintained after differentiation along either the myeloid or monocytic pathways. (f Clin Pathol: Mol Pathol 1995;48:M23-M27)

The Liver Research Laboratories, Queen Elizabeth Hospital, Edgbaston,

Birmingham B15 2TH

S C Afford

T Kakoullis

A J Strain

Department of

Histopathology, East

Birmingham Hospital,

Bordesley Green, East

Birmingham B9 5ST

J Oates

J Crocker

Correspondence to: Dr S C Afford.

Accepted for publication 24 October 1994
Hepatocyte growth factor (HGF) (scatter factor) is a potent mitogen for epithelial cells, ${ }^{12}$ particularly hepatocytes and biliary epithelial cells. ${ }^{34}$ Hepatocyte growth factor was first isolated from rat platelets, ${ }^{5}$ and its human gene homologue was characterised as a mature polypeptide composed of a 60 kilodalton $\alpha$ subunit linked by a single disulphide bridge to a 30 kilodalton $\beta$ subunit. ${ }^{6}$ The biological effects of HGF are mediated via a 190 kilodalton cell surface tyrosine kinase receptor, the proto-oncogene product cMET. ${ }^{7}$ Besides the mitogenic actions of HGF, other biological properties,
Keywords: Hepatocyte growth factor, cMET receptor. including morphogenesis, ${ }^{8}$ tumour cell cytotoxicity, ${ }^{9}$ neutrophil priming, ${ }^{10}$ lymphocyte chemotaxis, ${ }^{11}$ enhancement of B cell immunoglobulin secretion, ${ }^{12}$ metastasis, ${ }^{13}$ and stimulation of growth of haematopoietic progenitor cells of bone marrow ${ }^{14}$ have been reported. The effects of HGF on haematopoietic cells and the pathophysiological relevance remain uncertain. However, the broad spectrum of biological effects demonstrated in vitro, coupled with the widespread expression of the cMET receptor on a variety of cell types, suggest that HGF may have significant effects on haematopoietic cell function and differentiation.

In the present study we have used the promyelocytic cell line HL60 as a model to study the effects of HGF on myeloid cell differentiation. We have also attempted to assess expression of cMET throughout differentiation. HL60 cells produce HGF when stimulated with low concentrations $(1.6 \mathrm{nM})$ of 12-O tetradecanoylphorbol-13-acetate (TPA), ${ }^{15}$ but the effect of autocrine production of HGF on expression of the cMET receptor remains unknown. Whilst it has been reported that HL60 cells co-cultured with HGF may assume similar morphological characteristics to neutrophils, ${ }^{16}$ the effects of HGF on myeloid cell differentiation has not been investigated in greater detail.

To investigate these processes further, we have compared cells treated with purified recombinant HGF with cells treated with the standard differentiating agents dimethyl sulphoxide (DMSO) and TPA. In HL60 cells the latter two agents induce myeloid and monocytic differentiation pathways, respectively. We have assessed, by immunohistochemistry, myeloid differentiation using antibodies to human neutrophil elastase (HNE) ${ }^{17}$ and monocytic differentiation with antibodies to cathepsin $\mathrm{B}^{18}$ and MAC 387. ${ }^{19}$ Expression of cMET was also determined for cells treated with HGF, DMSO, and TPA.

\section{Methods}

HL60 cells were obtained from the European Collection of Animal Cell Cultures (Porton, Wiltshire, UK) as a mycoplasma-free culture. The tissue culture medium was RPMI 1640 basal medium supplemented with $10 \% \mathrm{v} / \mathrm{v}$ heat inactivated fetal calf serum, $2 \mathrm{mM} \mathrm{L}$-glutamine (Flow Laboratories, Herts, UK). Purified recombinant HGF was a gift from $\mathrm{Dr} T$ Ishii (Mitsubishi Kasei Corporation, Yokohama, Japan). The concentration and biological activity of the preparation was confirmed by en- 
zyme linked immunosorbent assay (ELISA) ${ }^{20}$ and a standard hepatocyte proliferation assay. ${ }^{21}$ Dimethyl sulphoxide, TPA, and the alkaline phosphatase substrate (naphthol AS-MX phosphate) were obtained from the Sigma Chemical Company (Poole, Dorset, UK). Antiserum to the human HGF receptor (polyclonal rabbit antihuman cMET) was obtained from Santa Cruz Biotechnology Inc. (Santa Cruz, California, USA). Alkaline phosphatase conjugated swine antirabbit immunoglobulins and mono-

\section{$+\mathrm{HGF}$}

HNE
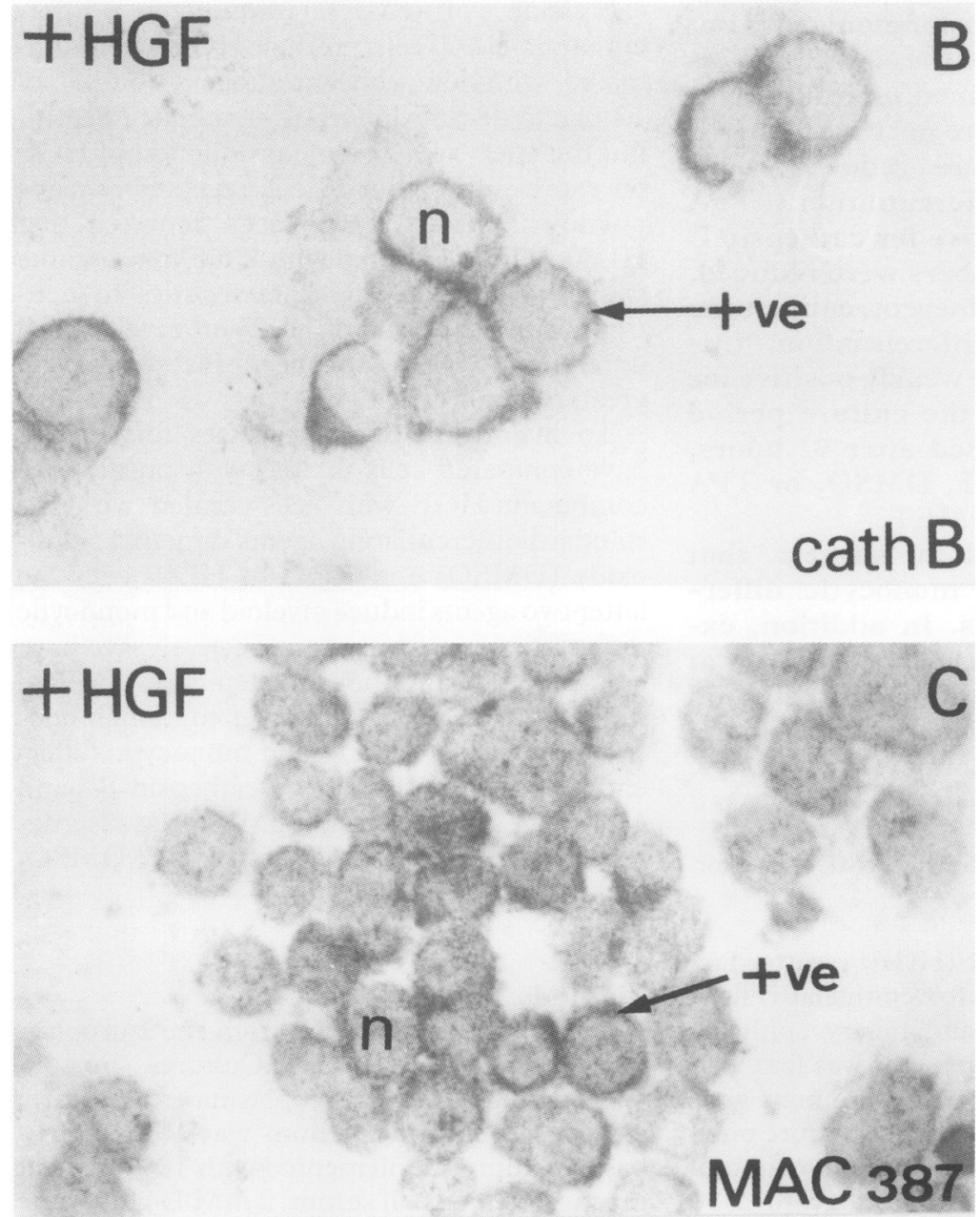

Figure 1 Immunohistochemical staining of cytospin preparations of HL60 cells treated with $35 \mathrm{ng} / \mathrm{ml} H G F$. HNE, B: cathepsin B (cath B), or C: MAC387. Cells in panel $A$ were negative for $H N E$. Therefore, the preparation has been counterstained with haematoxylin to facilitate visualisation of the cells; $n=$ nucleus. Arrows indicate negatively or positively staining cells. Original magnification $\times 630$. clonal mouse antihuman MAC387 were obtained from Dako Ltd. (High Wycombe, Bucks, UK). Polyclonal sheep anti-HNE and cathepsin B were obtained from The Binding Site (Birmingham, UK). Biotinylated secondary antibodies, non-immune blocking serum, horseradish peroxidase (HRP) labelled streptavidin/biotin complexes, and HRP substrate (diaminobenzidine) were supplied as Vectastain ABC detection kits (Vector Laboratories, Peterborough, UK).

Cells in the logarithmic phase of growth and with viability in excess of $95 \%$ (determined by the trypan blue dye exclusion test) were seeded in Linbro 24 well multiwell plates at $2 \times 10^{5} / \mathrm{ml}$ in tissue culture medium alone, or medium supplemented with $10 \% \mathrm{v} / \mathrm{v}$ DMSO, $1.6 \mathrm{nM}$ TPA, $16 \mathrm{nM}$ TPA, or HGF (35 ng/ml). At time intervals up to seven days, cells were harvested and viabilities and adherence determined, and cytocentrifuge preparations made for morphological and immunohistochemical analysis.

Briefly, MAC387 was localised as follows: firstly, endogenous peroxidase activity was blocked using $0.6 \%$ hydrogen peroxide in methanol, and non-specific binding of immunoglobulin was blocked with non-immune serum ( 1 in 10 dilution). Cytospins were then incubated with monoclonal mouse antihuman MAC387 ( 1 in 50 dilution) followed by biotinylated rabbit antimouse immunoglobulins and streptavidin/biotin/HRP complexes. Bound antibody was subsequently visualised with diaminobenzidine substrate. Human neutrophil elastase and cathepsin B were localised using polyclonal sheep anti-HNE or cathepsin B followed by biotinylated goat antisheep immunoglobulins and streptavidin/biotin/HRP complexes, and visualised as described above. Between stages, slides were washed three times with phosphate buffered saline. The cMET receptor was immunolocalised using a double antibody method, rabbit anti-cMET followed by alkaline phosphatase labelled swine antirabbit immunoglobulins. Bound antibody was visualised with naphthol AS-MX phosphate at $0.2 \mathrm{mg} / \mathrm{ml}$ in $0.1 \mathrm{M}$ TRIS/ $\mathrm{HCl}$ buffer containing levamisol (to block non-specific/endogenous alkaline phosphatase activity) at a final concentration of $1 \mathrm{mM}$. For each immunohistochemical stain, control sections were included where the primary antibody was substituted with non-immune serum. Experiments were performed in triplicate and multiple cytocentrifuge preparations were taken from each culture.

\section{Results}

EFFECTS OF HGF ON DIFFERENTIATION

MARKERS AND CELL PROLIFERATION

The cells treated with HGF were positive on staining for cathepsin B and MAC387 after 48 hours, and remained negative for $\mathrm{HNE}$, indicating that HGF was able to induce monocytic differentiation (fig 1 and table). Cell proliferation was monitored for HGF treated cells for up to seven days and viability remained in excess of $90 \%$. The difference in cell numbers between HGF treated cells and controls 
Summary of immunohistochemical staining of HL60 cells

\begin{tabular}{lllllll}
\hline & $\begin{array}{c}\text { cMET } \\
\text { O hours }\end{array}$ & 72 hours & $\begin{array}{l}\text { MAC387 } \\
72 \text { hours }\end{array}$ & $\begin{array}{l}\text { Cathepsin B } \\
72 \text { hours }\end{array}$ & $\begin{array}{l}\text { HNE } \\
72 \text { hours }\end{array}$ & $\begin{array}{l}\text { Adherence } \\
72 \text { hours }\end{array}$ \\
\hline HGF $(35 \mathrm{ng} / \mathrm{ml})$ & + & ++++ & ++++ & ++++ & Negative & No \\
DMSO $(10 \%)$ & + & ++ & Negative & Negative & ++++ & No \\
TPA $(16 \mathrm{nM})$ & + & ++++ & ++++ & ++++ & Negative & Yes \\
TPA $(1.6 \mathrm{nM})$ & + & ++++ & +++ & +++ & Negative & Yes \\
Control & + & +++ & Negative & Negative & Negative & No \\
\hline
\end{tabular}

Intensity of staining was assessed visually and scored from weak $(+)$ to intense $(++++)$.

did not reach statistica! significance, suggesting that HGF had no effect on cell proliferation (fig 2A).

After two to three days in culture, the cells treated with DMSO stopped dividing (fig 2B) and became positive for $\mathrm{HNE}$, but remained negative for cathepsin $\mathrm{B}$ and MAC387, confirming that DMSO induced differentiation of HL60 cells into myeloid-like cells (table). Cells treated with either 1.6 or $16 \mathrm{nM}$ TPA stopped dividing (fig 2B), became positive for cathepsin $\mathrm{B}$ and MAC387, and remained negative for HNE, a pattern consistent with differentiation into monocytes (table). The DMSO and TPA control experiments were not continued for more than three days because of a significant reduction in cell viability. Throughout the ex-
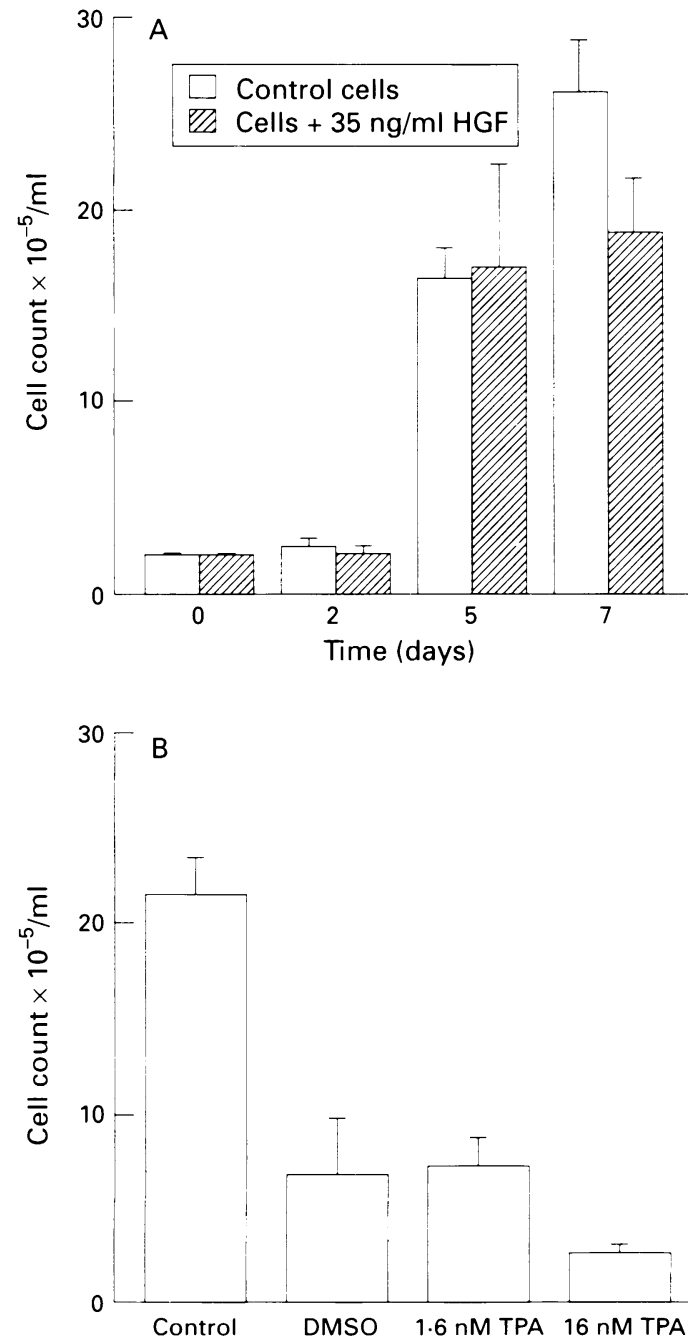

Figure 2 Effect of HGF and differentiating agents on cell proliferation. $A$. Cell counts at time intervals up to seven days. B: Cell counts at 72 hours for control cells; cells days. B: Cell counts at 72 hours for control cells; cells
$+10 \%$ v $v$ DMSO; cells $+1 \cdot 6 \mathrm{nM}$ TPA; and cells

$+16 n M$ TPA. Values are expressed as mean $(S D)(n=6)$. periments, the control cells remained negative for all markers of differentiation (table).

EFFECTS OF HGF AND DIFFERENTIATING AGENTS ON CMET EXPRESSION

Untreated HL60 cells were weakly positive for the cMET receptor (table and fig 3A). A fter a further three days in culture, the untreated cells showed an increase in intensity of staining (fig 3B), indicating that cMET expression increased spontaneously with time. Cells treated with DMSO for three days also showed immunoreactivity for cMET and remained nonadherent to the culture wells (table). When exposed to low or high concentrations of TPA, strong, evenly distributed cMET expression was observed and the cells became adherent to the culture wells (table). Cells treated with HGF also expressed cMET strongly after 72 hours (table and fig 3C). On visual assessment, cMET expression appeared to increase following culture with either TPA or HGF compared with control cells (table 1 and fig 3C).

\section{Discussion}

The present study has compared the effects of HGF on myeloid cell differentiation with those observed with the standard differentiating agents DMSO and TPA. The results show that HGF causes promyelocytic HL60 cells to become committed to monocytic differentiation. We have confirmed this using antibodies that are specific lineage markers for either neutrophils ${ }^{17}$ or monocytes. ${ }^{1819}$ In contrast to TPA, however, the HGF treated cells remained non-adherent and continued to proliferate at a similar rate to control cells. HL60 cells expressed cMET receptors and expression appeared to increase spontaneously with time and was maintained irrespective of myeloid or monocytic differentiation (table).

That exogenous HGF did not affect cell proliferation or promote adhesion to culture wells suggested that $\mathrm{HGF}$ induced partial monocytic differentiation. Our data do not concur with other findings, which suggested that HGF may induce myeloid differentiation. ${ }^{16}$ The reasons for this difference remain uncertain but may relate to the source or the biological activity of the HGF used. We had chosen a HGF concentration of $35 \mathrm{ng} / \mathrm{ml}$ to perform our experiments because this was the concentration (of our current HGF preparation) that induced maximum hepatocyte proliferation (the accepted index of biological activity). ${ }^{3+}$ We performed some initial experiments at concentrations up to $200 \mathrm{ng} / \mathrm{ml}$ but demonstrated no further effects (data not shown). In their recent publication Shima et $a l^{16}$ used HGF at a concentration of $200 \mathrm{ng} / \mathrm{ml}$. This is a very high concentration, even in vivo when abnormal or pathological circumstances prevail. ${ }^{20}$

Extrapolation of our conclusions to normal myeloid differentiation must be approached cautiously as HL60 cells are a cell line and their growth and function may be regulated differently compared with normal myeloid pre- 

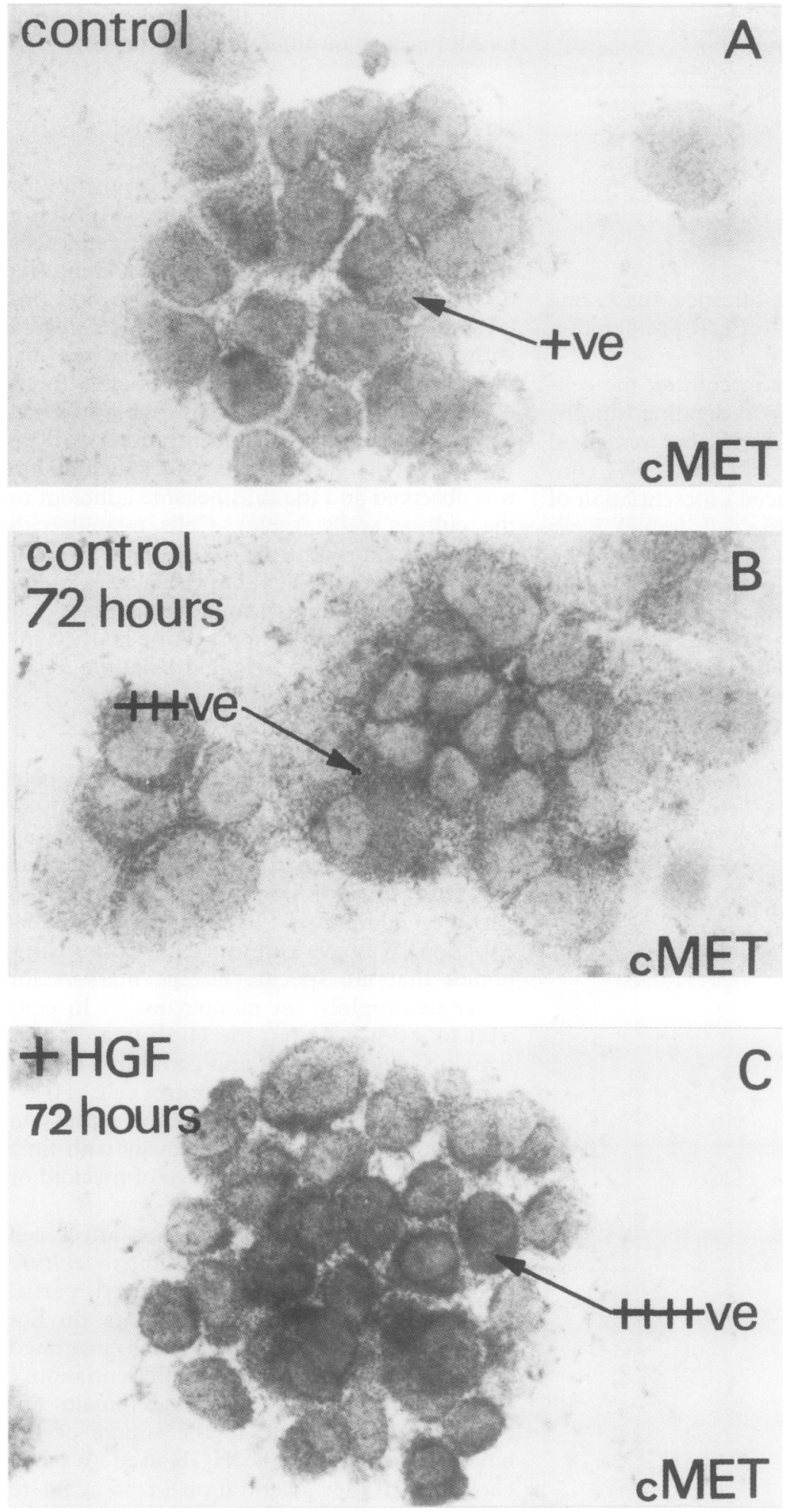

Figure 3 Immunohistochemical staining of cytospin preparations of HL60 cells for cMET. A: Cells alone at start of culture; B: cells alone after 72 hours; $C$ : cells plus recombinant HGF after 72 hours. Arrows indicate positive cMET staining, ranging from weak $(+)$ to intense $(++++)$. Original magnification $\times 630$.

cursor cells. Nevertheless, our study demonstrates that, in isolated culture systems, exogenous HGF may commit myeloid precursor cells to monocytic differentiation, but its effects are distinct from those elicited by TPA.

It has been shown previously that low concentrations of TPA $(1.6 \mathrm{nM})$ induce production of HGF by this cell line, but higher concentrations $(16 \mathrm{nM})$ do not. ${ }^{15}$ We confirmed this in our experiments by monitoring
HGF production after TPA treatment with a specific ELISA assay (data not shown). In HL60 cells HGF synthesis appeared to be induced only by the lower $(1.6 \mathrm{nM})$ concentration, an occurrence which may be related to the dose dependent effects of TPA on protein kinase $\mathrm{C}$ isoform activation, as shown in other cell systems. ${ }^{22-24}$ Thus, our data show that cMET expression does not diminish as a result of treatment with standard differentiating agents (DMSO and TPA), HGF, or when the cells are actively producing HGF themselves.

Hepatocyte growth factor can potentially influence a variety of leucocyte functions. ${ }^{10-12}$ It is possible therefore that maintainance of cMET expression is important during leucocyte differentiation, and subsequent migration of cells from the bone marrow compartment. The latter could explain why the HGF treated cells expressed monocytic markers but were not adherent. This would represent a logical stage of maturation for monocytic cells before release into the circulation, with adherence occurring at a later stage of maturation or activation. Similarly, retention of proliferative potential, once cells have left the bone marrow, may also be important. It is known that tissue macrophages can retain proliferative potential. ${ }^{23}$ Thus, from the present studies we postulate that TPA treated HL60 cells behave more like terminally differentiated, non-proliferating and possibly activated monocytes. By contrast, HGF treated cells behave more like cells at an earlier stage of differentiation, but committed to the monocytic pathway.

The precise role of HGF in the regulation of leucocyte function is likely to be dependent upon a complex set of variables including the presence of cofactors and the status of the cell population in terms of the proliferative/ maturation cycle. Previous work has shown that HGF can act synergistically with interleukin-3 on human bone marrow cultures, to enhance growth of haematopoietic progenitor cells. ${ }^{14}$ Hepatocyte growth factor did not affect cellular differentiation in those circumstances. The latter observations serve to highlight that the biological effects of this growth factor may differ, depending on the presence of cofactors and possibly the stage of the cell cycle. The data presented here show that the HL60 cell line will be of value in delineating these pathways.

We thank Dr David Adams for helpful comments during preparation of the manuscript. We are also grateful to Dr T Ishii and the Mitsubishi Kasei Corporation for providing the recombinant HGF. Technical assistance was provided by Geraldine McGuinness. Financial assistance was provided by the Medical Research Council, the Wellcome Foundation, and Celltech UK.

1 Rubin JS, Chan AML, Bottaro DP, Burgess WE, Taylor WG, Cech AC, et al. A broad spectrum human fibroblast derived mitogen is a variant of hepatocyte growth factor. Proc Natl Acad Sci USA 1991;88:415-19.

2 Weidner KM, Arakaki N, Vandekerckhove J, Weingart S, Hartmann G, Rieder $\mathrm{H}$, et al. Evidence for the identity. of human hepatocyte growth factor. Proc Natl Acad Sci of human hepatocyte

3 Strain AJ, Ismail T, Tsubouchi H, Arakaki N, Hishida $\mathrm{T}$, Kitamura N, et al. Native and recombinant human T, Kitamura $\mathrm{N}$, et al. Native and recombinant human Depatocyte growth factors are highly potent promoters of DNA synthesis in both $\mathrm{h}$
Invest $1991 ; 87: 1853-7$.

4 Joplin R, Hishida T, Tsubouchi H, Daikuhara Y, Ayres R, Neuberger JM, et al. Human intrahepatic biliary epithelia cells proliferate in vitro in response to human hepatocyte growth factor. $\mathcal{F}$ Clin Invest 1992;90:1284-9.

5 Nakamura T, Nawa K, Ichihara A. Partial purification and 
characterisation of hepatocyte growth factor from serum of hepatectomised rats. Biochem Biophys Res Commun 1984;122:1450-9.

6 Nakamura T, Nishizawa T, Hagiya M, Seki T, Shimonishi $\mathrm{M}$, Sugimura A, et al. Molecular cloning and expression of human hepatocyte growth factor. Nature 1989;342: 440-3.

7 Bottaro DP, Rubin JS, Falleto DL, Chan AML, Kmiecik TE, Vande Woude GF, et al. Identification of the hepatocyte growth factor receptor as the c-met proto-oncogene product. Science 1991;251:802-4.

8 Montesano R, Matsumoto K, Nakamura T, Orci L. Identification of a fibroblast derived epithelial morphogen as tification of a fibroblast derived epithelial morph

9 Tajima H, Matsumoto K, Nakamura T. Hepatocyte growth factor has potent anti-proliferative activity in various factor has potent anti-proliferative activity in
tumour cell lines. FEBS Lett 1991;291:229-32.

10 Jiang W, Puntis MCA, Nakamura T, Hallett MB. Neutrophil priming by hepatocyte growth factor, a novel cytokine. Immunology 1992;77:147-9.

11 Adams DH, Stiff L, Tanaka Y, Yannelli JR, Shaw S. Hepatocyte growth factor and transforming growth factor alph induce lymphocyte migration in vitro. Hepatology 1992; 95a:204.

12 Delaney B, Koh WS, Yang KH, Strom SC, Kaminski NE. Hepatocyte growth factor enhances B-cell activity. Life $S_{c i}$ 1993;53:89-93.

13 Jiang WG, Hallett MB, Puntis MCA. Hepatocyte growth factor/scatter factor, liver regeneration and cancer metastasis. Br F Surg 1993;80:1368-73.

14 Kmiecik TE, Keller JR, Rosen E, Vande Woude GF. Hepatocyte growth factor is a synergistic factor for growth of hematopoietic progenitor cells. Blood 1992;80:2454-7.

15 Nishino T, Kiase N, Sindo Y, Nishino N, Nishida T, Yasuda S, et al. Promyelocytic leukemia cell line HL60 produces human hepatocyte growth factor. Biochem Biophys Res Commun 1991;181:323-30.
16 Shima N, Itagaki $Y$, Nagao $M$, Yasuda $H$, Morinaga $T$, Higashio $\mathrm{K}$. A fibroblast derived tumour cytotoxic factor/ F-TCF (hepatocyte growth factor/HGF) has multiple functions in vitro. Cell Biol Int Rep 1991;15:397-408.

17 Crocker J, Jenkins R, Burnett D. Immunohistochemical demonstration of leucocyte elastase in human tissues. $\mathscr{f}$ Clin Pathol 1984;37:1114-18.

18 Burnett D, Crocker J, Vaughan ATM. Synthesis of cathepsin $B$ by cells derived from the HL60 promyelocytic leukaemi cell line. 7 Cell Physiol 1983;115:249-54.

19 Flavell DJ, Jones DB, Wright DH. Identification of tissue histiocytes on paraffin sections with a new monoclonal antibody. $₹$ Histochem Cytochem 1987;35:1217-26.

20 Tsubouchi H, Niitani Y, Hirono S, Nakayama H, Gohda $\mathrm{E}$, Arakaki N, et al. Levels of human hepatocyte growth factor in serum of patients with various liver diseases factor in serum of patients with various liver diseases
determined by an enzyme linked immunosorbent assay. determined by an enzym
Hepatology 1991;13:1-5.

21 McGowan JA, Strain AJ, Bucher NLR. DNA synthesis in primary cultures of adult rat hepatocytes in a defined medium: effects of epidermal growth factor, insulin, glucagon, and cyclic AMP. 7 Cell Physiol 1981;108:353-63.

22 Pelosin J, Vilgrain I, Chambaz EM. A single form of protein kinase $C$ is expressed in bovine adrenocortical tissue, as compared to four chromatographically resolved isozymes in compared to four chromatographically resolved isozymes in

23 rat brachem Biophys Res Commun 1987;147:382-91. phoproteins during commitment of HL60 cells to monophoproteins during commitment of HL60 cells to mono-
cyte differentiation: evidence for multiple protein kinase cyte differentiation: evidence for multiple p

24 Trayner ID, Clemens MJ. Stimulation of proliferation of HL60 cells by low concentrations of $12-\mathrm{O}$ Tetradecanoylphorbol-13-acetate and its relationship to the mitogenic effects of insulin. Exp Cell Res 1992;199:154-61.

25 Lalor PA, Mapp PI, Hall PA, Revell PA. Proliferative activity of cells in the synovium as demonstrated by a monoclonal antibody Ki67. Rheumatol Int 1987;7:183-6. 